Meta

Journal des traducteurs

Translators' Journal

\title{
Visual Aspects of Intercultural Technical Communication: A Cognitive Scientific and Semiotic Point of View
}

\section{Hanna Risku et Richard Pircher}

Volume 53, numéro 1, mars 2008

Le verbal, le visuel, le traducteur

The Verbal, the Visual, the Translator

URI : https://id.erudit.org/iderudit/017980ar

DOI : https://doi.org/10.7202/017980ar

Aller au sommaire du numéro

Éditeur(s)

Les Presses de l'Université de Montréal

ISSN

0026-0452 (imprimé)

1492-1421 (numérique)

Découvrir la revue

Citer cet article

Risku, H. \& Pircher, R. (2008). Visual Aspects of Intercultural Technical

Communication: A Cognitive Scientific and Semiotic Point of View. Meta, 53(1), 154-166. https://doi.org/10.7202/017980ar
Résumé de l'article

L'article vise à présenter une approche cognitive scientifique du rôle du verbal et du visuel dans la traduction des textes techniques. Tout d'abord, les auteurs discutent les différences entre les symboles et les icônes en respectant les perspectives des sciences cognitives et de la traductologie. Partant d'une définition du texte en tant qu'unité de communication (et de traduction) comprenant des aspects verbaux et visuels, l'article met dans la suite l'accent sur la dimension visuelle du texte à traduire. Cette discussion théorique fournit la base pour l'analyse des pratiques professionelles en ce qui concerne l'intégration de la dimension visuelle dans le processus de traduction. Une étude de terrain dans un service de traduction fournit les données empiriques. Les résultats de cette observation participante montrent l'influence des technologies de traduction (mémoires de traduction, systèmes de gestion de traduction, logiciels de localisation) sur le rôle du visuel dans le poste de travail moderne du traducteur. L'importance que ces technologies donnent au verbal rend de plus en plus difficile pour le traducteur de faire attention aux éléments visuels. Les auteurs en tirent la conclusion que la gestion critique et professionelle de la dimension visuelle doit être intégrée dans la formation des traducteurs.
Ce document est protégé par la loi sur le droit d'auteur. L'utilisation des services d’Érudit (y compris la reproduction) est assujettie à sa politique d'utilisation que vous pouvez consulter en ligne.

https://apropos.erudit.org/fr/usagers/politique-dutilisation/ 


\title{
Visual Aspects of Intercultural Technical Communication: A Cognitive Scientific and Semiotic Point of View
}

\author{
HANNA RISKU \\ Danube University Krems, Krems, Austria \\ hanna.risku@donau-uni.ac.at \\ RICHARD PIRCHER \\ Danube University Krems, Krems, Austria \\ richard.pircher@donau-uni.ac.at
}

\begin{abstract}
RÉSUMÉ
L'article vise à présenter une approche cognitive scientifique du rôle du verbal et du visuel dans la traduction des textes techniques. Tout d'abord, les auteurs discutent les différences entre les symboles et les icônes en respectant les perspectives des sciences cognitives et de la traductologie. Partant d'une définition du texte en tant qu'unité de communication (et de traduction) comprenant des aspects verbaux et visuels, l'article met dans la suite l'accent sur la dimension visuelle du texte à traduire. Cette discussion théorique fournit la base pour l'analyse des pratiques professionelles en ce qui concerne l'intégration de la dimension visuelle dans le processus de traduction. Une étude de terrain dans un service de traduction fournit les données empiriques. Les résultats de cette observation participante montrent l'influence des technologies de traduction (mémoires de traduction, systèmes de gestion de traduction, logiciels de localisation) sur le rôle du visuel dans le poste de travail moderne du traducteur. L'importance que ces technologies donnent au verbal rend de plus en plus difficile pour le traducteur de faire attention aux éléments visuels. Les auteurs en tirent la conclusion que la gestion critique et professionelle de la dimension visuelle doit être intégrée dans la formation des traducteurs.
\end{abstract}

\section{ABSTRACT}

This article presents a cognitive scientific view of the role of verbal and visual aspects in the translation of technical texts. The semiotic differentiation between symbols and icons is discussed from both the cognitive scientific and the translation studies perspectives. The article refers to the definition of text as a unit of communication (and translation) that includes both verbal and visual aspects and thus emphasises the function of the visual dimension in translation. The theoretical discussion is related to professional practices in the modern translation workplace: through its discussion of the results of a recent empirical field study based on participant observation over an extended period of time in a translation agency, the present research seeks to determine the extent to which the visual dimension can be taken into account in technical translation. In particular, the results point to the consequences of the use of translation technologies (translation memories, translation management systems, localisation software, etc.) in the modern translation workplace. The dominance of the verbal aspect induced by the use of some such technologies can make it increasingly difficult for translators to pay attention to the visual elements in translation. This stresses the importance of the inclusion of courses on the critical and professional use of translation technologies within translation studies programmes.

\section{MOTS-CLÉS/KEYWORDS}

technical translation, intercultural technical communication, visual signs, non-verbal communication, translation technologies 


\section{Introduction to Intercultural Technical Communication}

According to a number of experts, including for example Snell-Hornby, Jettmarová and Kaindl (1997), translation is the enabling of intercultural communication. The work of a translator is by no means restricted to verbal materials: it can also include all other forms of symbols and signals used in and relevant to communication. Technical communication and technical documentation - the subject of this article - is a prime example of this. It contains not only verbal elements, but also a large number of non-verbal elements (e.g., illustrations, icons, and images). Technical communicators and translators are responsible for producing texts that best suit the needs of their intended users, and these can include a combination of text, tables, figures, drawings, photos, etc. In some cases (a situation that seems to be on the increase in the modern translation and technical writing workplaces), they are even charged with the entire production process - from the planning and concept phases, through to the design and layout of the content and, ultimately, the release of the completed documentation. They are often the ones who are given the task of selecting the most suitable medium for the information in question and they design the documentation in line with the requirements presented by the medium they have chosen. They may find themselves working either on their own, in conjunction with the documentation and/or translation departments in a firm, or in a translation agency specialised in the field of technical communication.

With her theory of translatory action, Holz-Mänttäri repudiated back in 1984 the notion of the translator as a mere communicator of language, as someone who replaces elements of one language with corresponding elements of another (see HolzMänttäri 1984). She presented the work of translators as a professional service provided by experts who take into consideration all relevant verbal and non-verbal aspects in the production of translated material for use by others. Göpferich (1998) confirms that the areas of activity involved in technical translation and technical writing are increasingly converging and that translation studies graduates will find themselves working in heterogeneous and extremely dynamic environments.

If, for example, the graphics materials used in a translation require additional editing, translators (if they do not have the skills to actually do so themselves) will potentially have to work in cooperation with other experts, such as technical illustrators. Translators who work predominantly, for example, in a marketing environment can even need to acquire the skills needed to work with graphics tools. Technical illustrators focus on the visual representation of facts and context. In technical documentation projects, the aim of their work is to make the content of the finished article easier to understand for the target users. Similar to technical writers, they have to make sure that their work is in line with findings from the fields of biological learning and psychological didactics (for further details see Hoffmann 2002 and Ballstaedt 1996). Technical illustrators work in a number of fields including technical documentation, technical advertising and publishing.

\section{Intercultural Technical Communication as Cooperative Text Design}

Intercultural technical communication concerns itself with the creation of texts in a comprehensive, communicative sense. Consequently, it also includes the communication of non-verbal signs and design elements. These can range from figures, tables 
and background colours through to the navigation structures used and icons shown on the screen. In this article, we try to do proper justice to the communicative nature of this work by referring to it as technical communication, and not simply as technical editing or writing.

Communication does not necessarily depend on natural language. In fact, it is far more dependent on the possibilities that are open to and the ability of the communicating parties to interpret a given something as text - as a message that has the intention of influencing the actions of the interpreting party (see Posner 1994). All manner of different objects, from coughing, clothing, movements, gestures and images through to the spoken and written word, can be used and interpreted as text.

This article also concerns itself with the issue of interculturality in technical communication, since the source material generally has its roots - at least in part - in a different culture to that of the target recipient. By this, we do not simply mean that the source material was created in another language (in fact, this does not even necessarily have to be the case); instead we are referring to the fact that the source material has been defined and is characterised by the conventions, standards and constraints of another culture. As a result, it is not simply the verbal, language-related, interlingual part of a text that is relevant, but also, for example, the use of different communication channels, tools and instruments (e.g., telephone/letters/e-mails or CD/printed material) or the choice of either a more image-based or a more text-oriented presentation. Both this factor and the important aspect of professional text design are pushing the object of this article - and with it the field of intercultural technical communication in general - to centre stage in translation studies research.

If the translator has registered and properly understood the intentions of the customer, the question that then has to be answered is: What are the prevailing conventions in the target culture? What can in fact be said and done in the target situation and culture? The answers to these questions introduce another function of the translator's role: as experts on the target culture, they assume a consulting role and analyse how to complete the customer's order in a meaningful way. Is the form that is used in the source text also suitable for its function in the target culture or will this form have to be changed? Does this form of text actually even exist in the target culture? What effect could it have if it were to be introduced there for the first time? It should be borne in mind here that the verbal material is ultimately only one part of the whole. Editing this is of little use if no consideration is given as to whether and to what extent the facts and information it provides, the illustrations and photographs used and the way the translation will be used in the target culture will actually yield the desired results.

Another important issue here is the issue of localisation. Translators and technical communicators often work in this field, where visual information and signs naturally also play an extremely important role. Localisation is the process whereby a product is adapted to give it an acceptable look and feel for use in another country or cultural target market (locale; Esselink 1998). However, localisation is by no means restricted simply to the linguistic elements of such a product - it affects every aspect of the product's design, development and marketing. With their intercultural knowledge and experience, translators and technical communicators can also provide valuable additional support to the other phases in the localisation process. 


\section{The Cognitive Scientific Perspective}

To shed light on the visual aspects of intercultural technical communication from a cognitive scientific perspective, we must first take a closer look at communication as a form of intelligent behaviour based on cognition and thus at the relationship between language and the representation of reality.

The constructivist, cognitive scientific oriented approach of Situated, Embedded Cognition (for a good summary, see Clark 1997; for a discussion in the context of translation, see Risku 2004) postulates that perception - and with it cognition - is not a linear process of receiving and absorbing information; perception is far more subjective and is subject to an individual process of interpretation based on experience. External and internal input affect and change the flexible, recursive inner architecture. Meanings deliver the basis for the interpretation of future signals (and communicative symbols), which ultimately and by means of self-reference lead to us making sense of these signals - a sense that can be defined as the result of the interpretation of a given moment in time. Meanings are our existing, learned cognitive preferences and it is they who enable us to carry out our interpretation in the first place. Sense can be described here as the interpretation we allocate to a particular unit or object in the given situation (Risku 1998: 58, see also Keller 1992: 332). We maintain that both steps - the construction of meaning and the construction of sense - are necessary parts in the process and that they both have their roots in constructiveness. Describing cognition in this way - as a two-part process - not only takes its contextuality into consideration, it also helps us to provide a scientific explanation for phenomena such as metaphors, icons and symbols (for further details on this see both the next chapter and Risku 1998a: 66).

The self-referential nature of perception and cognition turn interpretations and the interpretation process itself into subjective, albeit not arbitrary processes. Different input channels (for example visual and auditory channels) are processed interactively in a network so that the interpretations can be related to each other (von Foerster 1979/1981). The interpretation of a word, a phrase or another symbol is influenced not only by other symbols, but also by earlier "multimedial" experiences as well as images, people and the whole situation in question.

According to empirical studies, visualisation enables people to rapidly and intuitively recognise objects (Horton 1994) and/or, for example, relationships of size (Norman 1993: 94f) and is therefore often recommended for use in the provision of technical information. Does this then mean that we can draw the conclusions that the brain works using internal images and that images are therefore cognitively ergonomic? This seems to be perhaps a little over simplified. The Situated, Embedded Cognition approach even goes as far as to relativise the basic notion of internal representations. The environment is not represented literally in the brain, it is far more an external resource in our thought process. Behaviour is based not simply on prior, abstracted experience, it is a dynamic system that involves the brain, the body and the environment. The term representation can therefore only be used to refer to this complete system or this complete process, but not to an internal representation based on similarity with the environment. According to Brooks (1995), human intelligence might well be modular in its design; these are, however, not modules like language, motor functions, visual or auditory areas of the brain, they are activities in situation (see also the subsumption architecture proposed by Brooks). 


\section{Signs: The Semiotic Perspective}

We use regular signs in our environment to establish correlations between events that repeat themselves. This is how, for example, we interpret dark clouds or particular flights of birds as a sign that it is about to rain and - to use the example given by Grice - red spots on our face as a sign that we might have measles (see Keller 1992: 334). In semiotics, these events or signs are described as symptoms that enable us to predict things: they become "signs for something that [...] will happen sooner or later" (Eco 1973/1985: 246) or an indication of something that is part of a greater whole (just like spots are one of the symptoms of measles; see Keller 1992: 335). Pierce called this first group of signs indices that occur as a result of spatial-temporal coexistence (Jirànek 1992: 373).

Of utmost importance for understanding translation and intercultural communication is the realisation that terms and signs are not primarily or solely verbal or communicative (inter-subjective). In principle, anything that can be perceived and interpreted can be seen as a sign - interpreting is nothing more than a linking of the perceivable to the not directly perceivable (Keller 1992: 328f). If perception represents the peripheral, selective and constructive processing of sensory impressions in cognitive systems, and this perception is embellished in the brain to produce an understandable whole, then information processing is in essence an interpretation of the environment.

This line of thinking follows a different route to the one taken by Wolfram Wilss, who remains true to a normative view of the world and demands that interpreting only be referred to in a hermeneutic context (Wilss 1992: 120), whereby it should also be noted that Wilss sees hermeneutics outside the literary sciences as a futile digging for meaning (1992: 129). In contrast to this opinion, we feel there have been quite a number of insights in this field that point to universal principles of cognition: the hermeneutic principle, according to which we can only recognise something with the help of pre-judgements is a candidate that needs to be taken seriously (see Gadamer 1966/1976). There can be no sign without an interpreter, who perceives the sign and applies his/her own knowledge to it. To become signs, objects must be interpreted as such, and to do so we need terms like prior knowledge.

Translators can only interpret things using knowledge (meanings); it is this knowledge that makes the situation understandable. This explains the semiotic differentiation between meaning and sense: the meaning of the sign is not that which we understand, but that which makes the sign understandable (Keller 1992: 332). Meaning is therefore a recognised regularity or a typical context, a guideline (knowledge) that enables us to interpret signs or other objects; sense is the goal of the interpretation, an individual understanding of the sign in the given context that supports the current action (see also de Beaugrande and Dressler 1981: 88). Meaning and sense are thus only methodologically different phases of interpretation. With regard to the different translation strategies open to a translator, it therefore becomes clear that knowledge on its own is simply not enough: an attempt to translate something based solely on knowledge might not be meaningless, it is, however, senseless. 


\section{The Visual in Technical Communication: A Categorisation}

According to Ballstaedt (2003), the labels used to describe non-verbal forms of representation are currently applied in a very inconsistent and non-unified manner: each author decides what he/she considers to be a drawing, a visualisation, a diagram, a chart, a figure or an illustration. Our use of these terms is based on the categorisation proposed by Ballstaedt (2003), which itself has its roots in psychology.

\section{Non-representational images}

These include images that do not actually represent anything in particular, but instead communicate an aesthetic experience. Examples of non-representational images are graphic elements, ornaments, decorations or abstract images. They can be a determining factor in establishing the first image, as can be the case, for example, with a corporate logo. They can be unassuming and undemanding in that they do not require any interpretative effort on the part of the beholder, but they can also induce the projection of meanings.

\section{Depictions, representational images}

From a perception psychology point of view, a representational image is a treated surface that reflects a collection of light rays in a similar way to its natural original. It belongs to the class of informative and didactive images. Visual information of this kind is often difficult to communicate in verbal form.

The acts of processing and understanding images are often underestimated, and this is the reason for the popular myth that by using image-based forms of documentation, the time, effort and costs involved in translation can be saved. However, images cannot always be readily understood at first glance, they have to be analysed and understood in the context of the specific culture. What does the image represent? Why did the author(s) use that particular image? Effective use of visual images is not simply a matter of course, it is something that must be trained and practised ("visual literacy").

We differentiate between types of images with decreasing levels of concreteness which, in addition to their basic communicative functions, each also have their own special strengths (see Ballstaedt 2003):

- Real images: photographs, realistic drawings and paintings.

- Textured images: similar to photographs but with less detail, where surface characteristics and lighting are emphasised to increase the spatial effect.

- Line-based images: line drawings, which reduce reality to corners, edges and other forms, thereby reducing the image to its key characteristics.

- Outline images: only show the silhouette of an object (used, for example, to indicate danger).

- Diagrammatic images: circuit diagrams and schematised maps; images of this kind can be exaggerated to caricature level. 


\section{Charts, analytical images}

Charts represent links between different elements. Comprehensive charts provide orientation support in complex structural relationships, while simple charts help us to memorize things. The understanding of charts assumes that spatial arrangements can be translated into conceptual relationships (e.g., cause-effect or superordinatesubordinate). As a result, they are strongly influenced by culture-specific conventions such as reading direction (from left to right or from right to left). We can differentiate here between the following basic types of charts (see Ballstaedt 2003):

- Category (word) tables: in a qualitative table, the contextual relationships between categories are repeated so that they can be categorised and visualised in rows and columns. A table can be used to present information more clearly than with formulated text. However, it may also be dependent on prevailing verbal-syntactic (and thus culture- specific) correlations and therefore require a great deal of editing in translation. The use of short keywords and headings can also lead to problems in understanding.

- Time charts: events are plotted on a time axis either retrospectively or prospectively, e.g., in project management.

- Flow charts: this form of visualisation was developed in informatics initially to represent program sequences, but was later extended to include all manner of events and different processes. Flow charts present procedural knowledge as a sequence of actions and decisions. In technical documentation, the layout of flow charts is now standardised (e.g., in Germany by DIN Standard 66001).

- Organisational charts: these charts have their roots in sociology and are used to represent the relationships between individual persons and groups. The internal structure of an organisation, including its departments and their areas of responsibility are visualised using organisational charts.

- Mind maps: this form of chart comes from research into artificial intelligence and is used to represent conceptual, definable knowledge.

\section{Diagrams}

Diagrams are used to visualise quantitative relationships. The exact values remain visible, allowing rough visual comparisons to be made quickly and easily. Diagrams are graphical, culture-specific conventions, and their use has to be learned. Studies repeatedly show that many people are not able to understand even the simplest of diagrams (Ballstaedt 2003: 17). Diagrams are a form of visualisation, which often make use of visual manipulation: the data shown might be numerically correct, but the visualisation either weakens or strengthens certain messages. There are a vast number of different types of diagram available. The following list gives examples of some of the more commonly used types:

- Pie charts are useful for displaying the sizes of the different parts that go to make up a particular whole.

- Horizontal bar charts are particularly useful for visualising a ranking order.

- Vertical bar charts use columns to visualise, for example, frequency distributions and changes in quantity.

- Line or curve graphs are a further development of the bar chart and are used, for example, in a time series with a large number of measurement points to visualise the relationships between the different pieces of information. 
- Range diagrams visualise the relationship between two variables. A relationship exists if the plotted points are grouped around a line or curve.

\section{Pictograms, icons}

A pictogram is a simple, schematised symbol or picture that, for example, induces (hint, instruction) or suppresses (warning, ban) a particular action. The use of pictograms is very popular above all in the computer world (in user interfaces). Depending on the situation and the beholder, they can be interpreted as icons or symbols: US Americans recognise the mailbox or trashcan symbols as icons, whereas many Europeans have had to learn to understand these pictograms as symbols, since post boxes and rubbish bins look very different in their own reality. Pictograms cannot therefore simply transmit a message "across languages and cultures."

\section{Maps}

Maps present an image from above that usually also contains non-visible symbolised information. Maps are used to provide us with spatial orientation. Map-reading is something that has to be learned - it requires its own set of skills. Since the information they contain can often be partly very abstract, maps are subject to language- and culture-specific conventions.

\section{Complex images: isotypes and infographics}

Isotypes are a special form of visualising statistical data (International System of Typographic Picture Education). They should transmit a message to people who might otherwise be at a loss to interpret the associated numbers and statistics. Infographics were originally developed for use in journalistic print media, but have since gone on to find their use in technical communication (see Jansen 2003). They are a combination of text and image in which verbal and non-verbal forms of representation are closely linked to one another. Their aim is to provide access to and make complex relationships understandable. However, they can at times ask too much of the reader and/or user. (For further discussion of the categorisation of images, see Ballstaedt 2003.)

\section{Empirical Studies}

Let us now relate these theoretical discussions to professional practices in the translation and technical communication workplace. To enable us to do so, we will refer to two different qualitative studies we carried out recently to examine modern translation management practices: an interview study of intercultural technical communicators and a field study involving the on-site observation of daily working life in a translation agency in Vienna over an extended period of time (for a comprehensive report of these studies, see Risku 2004). 


\section{Interview study: visual competences \\ in intercultural technical communication}

The main aim of the interviews was to examine the personal experiences of former translators who had since migrated to the field of technical communication. Six qualitative, semi-structured, individual interviews lasting about two hours each were carried out in a neutral, non-business environment, and a complete transcript produced of each interview. The analysis of these interview transcripts provided us with the following results.

On a theoretical level, translation competence would appear to provide an excellent foundation for professional development into the field of international technical communication. Professional translators are capable of analysing both text and situation, carrying out research on requirements and conventions, managing intercultural communication projects and writing reader- and user-oriented texts. Thus, their work includes several of the components required in the field of international technical writing. However, the results also highlighted some important differences between translation and technical communication, some of which are strongly related to the area of visual information.

The strong focus on the verbal in translation training and practice was seen as a hindrance in technical communication, since it basically ignored the use of images and other media. Conversely, the interviewees saw interpreting lessons as good preparation for technical communication, since it had trained them in how to make their own notes, use symbols, recognise visual elements and communicate content instead of reformulating verbal material. They described the design process and the use of graphics and other tools as a new and uncharted field. Similarly, combining and working with both text and images was a new skill they had had to learn and very much enjoyed.

\section{Field study: handling visual information in translation management}

A field study was carried out involving the on-site observation of daily working life in a translation agency in Vienna over a period of four weeks, whereby the members of the research team assumed the role of participatory observers. The resultant case study offers a practical illustration of some of the key aspects of modern translation management and the role played by technology. This study also revealed the importance of visual information. In general, however, the issues involved were not the culture-specific elements of the images, but the establishing of coherence between image and text and the need for images as an aid to understanding and thus translation.

Here some brief background information on the setting for the field study. At that time, the agency had five staff (all female): the Managing Director (with a Business Studies degree) and four Project Managers (all with Translating/Interpreting degrees). They worked with translators and interpreters all around the world, as well as with a number of other translation agencies. To remain at the forefront of translation technology, they also had a cooperation agreement with a major supplier of language technology tools. The majority of their customers were large corporations who regularly needed material translated into multiple target languages. 


\section{Images as aids to understanding}

The agency staff laid particular emphasis on gathering as much context as possible on the source text right from the outset. For example, customers were requested to provide reference materials (i.e., previously translated texts on similar subjects), plans, drawings or images.

One of the staff said: "It's no wonder they [the translators] always want photos!" Images provide important background information of particular use, for example, in the creation of technical documentation. In one case, however, the agency encountered great problems translating a catalogue for ladies clothing. The translators were not provided with any accompanying pictures and "had to translate the catalogue before the new collection was even ready." Translating and proofreading expressions like "decorative ribbon" or "integrated push-up panty" without a picture to refer to proved extremely difficult even for an agency specialised in the translation of "delicate" texts.

The agency does its utmost to avoid putting its translators in such a situation. In another project, they organised a special training course for the translators with the customer. The translators spent three days (of their own time) at the customer's site learning how to weld. The aim of this training was to deepen the translators' practical knowledge of the process and thus enable them to translate more quickly and produce higher quality results (thereby "covering" the training costs they had had to invest). However, "translators sometimes require convincing before they will agree to give up three days of their time free of charge."

\section{Layout: words in context}

In the words of the agency manager: "Layout is important for translators - they need to see what exactly the image is trying to say."

Along with the contextual aspects, formal aspects also play an important role in a translation. Staff always try to obtain a copy of the source text in its original layout (as a .pdf file). The layout not only helps the translator to establish a better picture of the source text, it also delivers important constraints for the creation of the target text. In many cases, the client wants to keep as near to the original layout as possible; in other words, the target text has to fit into the available layout. It can also happen that the layout is handled by a graphic designer who is not familiar with the target language. In cases like this, the translation not only has to follow the design of the source text (so that the layout can be reused), it must also be recognisable simply from the formatting. In one project, for example, a user handbook was to be translated into Portuguese, and the customer - "who did not speak any Portuguese" would "handle the layout himself"!

The greater the similarity of the translation with the .pdf the better. In this case, for example, warnings were printed in the pdf in boldface, formatting that was lost in the exported text. The translated warnings also had to be shown in boldface so that the Portuguese designers would know what to highlight in the completed document.

\section{The Influence of Translation Technologies}

Nowadays, a number of different technologies are available to support the translation process, including translation memory systems, localisation software, machine trans- 
lation tools, specialised project management tools, internet platforms and virtual communities.

Although many of these tools are still targeted primarily at the verbal aspects of translation, new capabilities are continually being developed and added, and the role played by such technologies, particularly, for example, in the field of localisation software, should not be ignored in a comprehensive discussion of verbal and visual aspects in technical translation. Clients increasingly now expect translators and technical communicators to work with a wide range of tools and often see it as a matter of course that they have access to and are familiar with such tools. The following section provides a brief overview of some of the tools available, a description of their use and their relevance for the visual aspect of technical translation.

Translation Memory Systems are useful for handling large translation volumes, particularly when a project is coordinated centrally and consistency plays an important role. However, there is the risk that solutions devised for a different context may dominate the current text. This can be aggravated by poor source and reference material or problems with file formats (e.g., where the source file has to be converted). Consequently, in some contexts the agency staff considered translation memory systems more a hindrance than a help.

Translation memories can only contribute to the quality of a translation and increase cost-effectiveness if a number of criteria and requirements are met (such as availability of specific text formats, well-considered program parameters, high-quality reference material and a link to a well-maintained terminology management system).

The issues that have to be considered are not whether a translation memory system should be used, but rather which one is the most appropriate for the actual cooperation and what are the economic benefits of using such a system. If the individual members of a virtual team use different systems, these obviously have to be compatible.

From a quality aspect, translation memory systems have advantages and disadvantages. Using a client's translation memory provides the translator with access to existing context and "history," thereby increasing productivity. However, since translation memory systems are based on a comparison of individual linguistic elements, they follow the amateurish strategy of translation as a simple substitution of linguistic elements in different languages. They do not support the assessment of the adequacy or cultural transfer of the images used in any way (an aspect which, by the way, also applies to machine translation systems). The ignorance of the visual is, of course, acceptable and understandable from the technological point of view. However, it limits the adequacy of the tools and steers the practice of translation in a particular direction: towards an improper dominance of the verbal at the cost of the visual.

According to Wagner (1997: 429), a technology induced way of working often assumes the role of a "powerful standard image from which it is difficult to step back." This is a central issue in Computer Supported Cooperative Work, where the discussion focuses on how technology may help to encourage flexibility and creativity, support legacy-based work methods and even allow for unconventional or "quick and dirty" methods.

Localisation software offers a good example of the role translation technology can play in supporting translation skills and enabling translators to work on more than just verbal material. The possibilities offered by such tools support cooperative translation and can improve the quality of a translation. They allow translators to 
view the actual user interface during the translation process and thus take the context into consideration. Translators can adapt some items themselves (e.g., button size), or delegate more extensive program changes to the software developers (e.g., a change of syntax in a dialog box or navigation path). In this way, the entire software product becomes the object of the translation.

Localisation tools allow translators to endow products with their knowledge of the links between linguistic, formal and cultural requirements (cf. Freigang 1996). Without them, translators have to decode words, phrases or sentences out of context when translating software programs and then wait for the language elements to be imported into the target language version of the product before verifying the effects of their efforts - a laborious process whose results are all too familiar (from the early days of computer technology).

\section{Conclusion}

As the above discussion shows, the role of visual aspects is becoming increasingly important alongside that of verbal aspects in the modern translation and technical communication workplaces. Translators and technical communicators must learn to pay the necessary attention to these visual aspects - from symbols, colours and icons right through to the final layout of the finished translation product - and take them into account in the translation process. There are already tools available to help them to do so, however, translators and technical communicators alike must take care to ensure that the dominance of the verbal in existing translation technologies does not lead them to overlook the importance of the non-verbal aspects.

There is much that can be done in Translation Studies programmes to prepare translators and technical communicators for their future roles. Such programmes have to include appropriate courses to raise awareness of the importance of the non-verbal among future translators as well as to teach them how to use available translation technologies in a critical and professional manner. The use of technology in translation management must increasingly assume a pragmatic, functional perspective. Visual aspects as a central issue in translation must be properly considered in the development of current and future translation tools, while research and teaching must treat the visual aspects of translation in their context as part of a whole situation, pushing nonverbal, social and communicative factors into the centre of the analysis.

\section{REFERENCES}

Ballstaedt, S.-P. (1996): “Bildverstehen, Bildverständlichkeit - Ein Forschungsüberblick unter Anwendungsperspektive," in KRINGs, H. P. (ed.), Wissenschaftliche Grundlagen der Technischen Kommunikation (= Forum für Fachsprachen-Forschung 32), Tübingen, Narr, pp. 129-190.

Ballstaedt, S.-P. (2003): “Technische Kommunikation mit Bildern," in Hennig, J. and M. TJarks-Sobhani (Hgg.), Visualisierung in Technischer Dokumentation (= tekom Schriften zur Technischen Kommunikation 7), Lübeck, Schmidt-Römhild, pp. 11-31.

Beaugrande, R. A. De and W. U. Dressler, (1981): Einführung in die Textlinguistik, Tübingen, Niemeyer.

Brooks, R. (1995): "Intelligence without reason," in Steels, L. and R. Brooks (eds.), The Artificial Life Route to Artificial Intelligence. Building Embodied, Situated Agents, Hillsdale, Lawrence Erlbaum Associates, pp. 25-81. 
Clark, A. (1997): Being There. Putting Brain, Body, and World Together Again, Cambridge, MIT Press.

Eco, U. (1973/1985): Über Gott und die Welt. Essays und Glossen. Deutsch von Burkhart Kroeber, München.

Esselink, B. (1998): A Practical Guide to Software Localization, Amsterdam/Philadelphia, John Benjamins.

von Foerster, H. (1979/1981): "Das Konstruieren einer Wirklichkeit. Übersetzung aus dem Englischen: Walter Frese," in Watzlawick, P. (Hg.), Die erfundene Wirklichkeit. Wie wissen wir, was wir zu wissen glauben? Beiträge zum Konstruktivismus, München, Piper, pp. 39-60.

Freigang, K.-H. (1996): “Software-Lokalisierung. Ein Gegenstand übersetzungswissenschaftlicher Reflexion?," in Lauer, A., Gerzymisch-Arbogast, H., Haller, J. and E. Steiner (eds.), Übersetzungswissenschaft im Umbruch. Festschrift für Wolfram Wilss zum 70. Geburtstag, Tübingen, Narr, pp. 135-146.

Gadamer, H.-G. (1966/1976): "Die Universalität des hermeneutischen Problems," in Kleine Schriften I. Philosophie. Hermeneutik 2, unveränderte Auflage, Tübingen, Mohr, pp. 101112.

GöPFERICH, S. (1998): Interkulturelles Technical Writing: Fachliches adressatengerecht vermitteln. Ein Lehr- und Arbeitsbuch (= Forum für Fachsprachen-Forschung 40), Tübingen, Narr.

Hoffmann, P. (2002): "Polishing your pictures," presentation given in Tampere on the 4/10/02, $<\mathrm{http}: / /$ www.chez.com/crt/ressources/textes_redac_tech_en.htm $>$.

Horton, W. K. (1994): The Icon Book: Visual Symbols for Computer Systems and Documentation, Hoboken, NJ, John Wiley and Sons.

Holz-Mänttäri, J. (1984): Translatorisches Handeln. Theorie und Methode, Helsinki, Suomalainen Tiedeakatemia (Annales Academiæ Scientiarum Fennicæ B 226).

Jansen, A. (2003): "Wie viel Infographik braucht die Technische Dokumentation?," in Hennig, J. and M. TJarks-Sobhani (Hgg.), Visualisierung in Technischer Dokumentation (= tekom Schriften zur Technischen Kommunikation 7), Lübeck, Schmidt-Römhild, pp. 195-212.

JiRÁNeK, J. (1992): Symptom, Index, Konnotation, Zeitschrift für Semiotik 4, pp. 373-375.

Keller, R. (1992): “Zeichenbedeutung und Bedeutungswandel," Zeitschrift für Semiotik 4, pp. 327-366.

Posner, R. (1994): "Zur Genese von Kommunikation - Semiotische Grundlagen," in Wessel, K.-F. and F. Naumann (Hgg.), Kommunikation und Humanontogenese (= Berliner Studien zur Wissenschaftsphilosophie \& Humanontogenetik 6), Bielefeld, Kleine Verlag, pp. 384429.

Norman, D. A. (1993): Things that Make Us Smart. Defending Human Attributes in the Age of the Machine, Reading, Addison-Wesley.

Risku, H. (1998): Translatorische Kompetenz. Kognitive Grundlagen des Übersetzens als Expertentätigkeit, Tübingen, Stauffenburg.

Risku, H. (2004): Translationsmanagement. Interkulturelle Fachkommunikation im Informationszeitalter, Tübingen, Narr.

Snell-Hornby, M., Jettmarová, Z. and K. Kaindl (1997): Translation as Intercultural Communication: Selected papers from the EST Congress, Prague 1995, Amsterdam, John Benjamins.

WAgner, I. (1997): “On Multidisciplinary Grounds: Interpretation Versus Design Work," in Bowker, G. C., Star, S. L., Turner, W. and L. Gasser (eds.), Social Science, Technical Systems, and Cooperative Work. Beyond the Great Divide, Mahwah, New Jersey, Lawrence Erlbaum Associates, pp. 415-432.

WiLss, W. (1992): Übersetzungsfertigkeit. Annäherungen an einen komplexen übersetzungspraktischen Begriff, Tübingen, Narr. 